\title{
Variabilidade Espacial da Comunidade Bacteriana Intestinal de Suínos Suplementados com Antibióticos ou Extratos Herbais
}

\section{Adriana Ayres Pedroso ${ }^{1}$, Liliana Lotufo Oetting ${ }^{2}$, Carlos Eduardo Utiyama ${ }^{2}$, José Fernando Machado Menten ${ }^{3}$, Marcio Rodrigues Lambais ${ }^{4}$, Valdomiro Shigueru Miyada ${ }^{5}$}

\begin{abstract}
RESUMO - Este trabalho foi conduzido para se avaliar o efeito da suplementação com antimicrobianos (associação de 50 ppm de colistina, 50 ppm de bacitracina de zinco e 50 ppm de olaquindox) ou extratos herbais (à base de tomilho, cravo e orégano, na concentração de 0 ppm, 700 ppm, 1.400 ppm e 2.100 ppm) sobre a comunidade de Bacteria do duodeno, jejuno, íleo e ceco de suínos com 56 dias de idade. Foi utilizada a técnica de eletroforese em gel de poliacrilamida com gradiente de desnaturação de amplicons da região V3 do rDNA 16S. O antibiótico e o extrato herbal proporcionaram diminuição na incidência de diarréia. O extrato herbal, em diferentes concentrações, proporcionou desempenho similar ao dos animais suplementados com antibiótico. O nível de 2.100 ppm de extrato herbal proporcionou melhor ganho de peso que os menores níveis testados. O número de amplicons detectados variou em função do segmento intestinal analisado e da suplementação com promotores de crescimento. Foi possível estabelecer relações entre o número de amplicons observados nos quatro segmentos do trato intestinal, suplementação adotada, o ganho de peso diário e a incidência de diarréia. As estruturas da comunidade de Bacteria do trato intestinal de suínos apresentaram maior similaridade em função do local de amostragem que em relação ao promotor de crescimento suplementado.
\end{abstract}

Palavras-chave: desempenho, microbiota, poliacrilamida, promotores de crescimento, suínos

\section{Spacial Variability of Intestinal Bacterial Population of Swine Supplemented with Antimicrobial or Herbal Extracts}

\begin{abstract}
This trial was conducted to evaluate the effect of antimicrobial supplementation (association of 50 ppm of colistin, $50 \mathrm{ppm}$ of zinc bacitracin and $50 \mathrm{ppm}$ of olaquindox) or herbal extract (based on thyme, clove and oregano at levels of 0, 700, 1,400 and 2,100 ppm) on Bacteria population of duodenum, jejunum, ileum and cecum of swine at 56 days old. Denaturing gradient technique in polyacrylamide gel electrophoresis (DGGE) of amplicons from 16S rDNA V3 region was used. The number of detected amplicons changed according to intestinal segment analyzed and supplementation with growth promoter. Antibiotic and herbal extract decreased diarrhea incidence. Performance of animals supplemented with increasing levels of herbal extract and antibiotic was similar. The highest level (2,100 ppm) of herbal extract showed greater values of weight gain. It was possible to determine relations among the number of amplicons observed in the four segments of intestinal tract, growth promoter, daily weight gain and diarrhea incidence. The structure of Bacteria population of the intestinal tract of swine showed higher similarity, due to the sampling site than the growth promoter.
\end{abstract}

Key Word: growth promoters, performance, polyacrylamide, microbiota, swine

\section{Introdução}

Antimicrobianos são largamente utilizados como promotores de crescimento para suínos. Especula-se que os antimicrobianos possam eliminar ou controlar microrganismos que causam queda no desempenho animal. Ultimamente, esta prática está sujeita a restrições, pois acredita-se que o uso contínuo desses produtos pode resultar na seleção de microrganismos resistentes à molécula utilizada (Fairbrother, 1999).
Como alternativa, têm-se pesquisado inúmeros produtos, como os extratos herbais, que são constituídos por óleos essenciais que contêm substâncias, algumas com princípios ativos com efeito promotor de crescimento (Menten, 2002). Esses produtos seriam utilizados com o intuito de melhorar os índices zootécnicos, pois poderiam estimular as enzimas digestivas (Kamel, 2001), aumentar a digestibilidade e absorção de nutrientes (Rostagno et al., 2001) ou possuir atividade antibacteriana (Deans et al., 1987).

\footnotetext{
${ }^{1}$ Zootecnista, Doutora, Dep. de Zootecnia da ESALQ/USP, Piracicaba/SP. Bolsista de Doutorado FAPESP

2 Zootecnista, aluno de Doutorado, Dep. de Zootecnia da ESALQ/USP, Piracicaba/SP. Bolsista de Doutorado FAPESP.

3 Docente, Dep. de Zootecnia da ESALQ/USP, Piracicaba/SP. Bolsista do CNPq. E.mail: jfmmente@esalq.usp.br

4 Docente, Dep. de Solos e Nutrição de Plantas, Piracicaba/SP. Bolsista do CNPq.

5 Docente, Dep. de Zootecnia da ESALQ/USP, Piracicaba/SP
} 
Existem controvérsias sobre a possível seleção que os promotores de crescimento tradicionais ou alternativos promovem na microbiota intestinal. Técnicas de cultivo de microrganismos podem não ser eficazes para a avaliação da possível modificação da microbiota ocasionada pelos promotores do crescimento, pois dependem de meios seletivos e outras condições artificiais de crescimento. Nos últimos anos, técnicas moleculares que não necessitam do cultivo bacteriano, como a eletroforese em gel com gradiente de desnaturação (DGGE) de amplicons de rDNA 16S, têm sido utilizadas para caracterizar ecossistemas complexos. Segundo essa técnica acima, o DNA total do habitat de interesse é extraído e uma região hipervariada do rDNA $16 S$ é amplificada pela reação em cadeia da polimerase. Amplicons de DNA com mesmo tamanho, mas com composição distinta, podem ser separados pela eletroforese em gel com gradiente de desnaturação, gerando um perfil genotípico da comunidade.

O objetivo neste estudo foi avaliar a variabilidade espacial da estrutura da comunidade de Bacteria ao longo do duodeno, jejuno, íleo e ceco de suínos suplementados com antimicrobianos e extratos herbais em diferentes concentrações, além de verificar o desempenho zootécnico dos animais e as possíveis relações entre a comunidade de Bacteria observada nos diferentes segmentos intestinais.

\section{Material e Métodos}

Para a realização do experimento, foram utilizados 40 suínos de linhagem comercial, com 35 dias de idade, em delineamento de blocos casualizados, com cinco tratamentos (ANT - suplementação dietética com 50 ppm de bacitracina de zinco, 50 ppm de colistina e 50 ppm de olaquindox; E0 - ausência de suplementação com promotores de crescimento; E700 - suplementação dietética com 700 ppm de extrato herbal à base de cravo, orégano e tomilho; E1.400 - suplementação dietética com 1400 ppm de extrato herbal à base de cravo, orégano e tomilho; E2.100 - suplementação dietética com 2100 ppm de extrato herbal à base de cravo, orégano e tomilho) e quatro repetições.

Os extratos herbais consistiram de óleos essenciais à base de cravo (contendo o princípio ativo eugenol), orégano (contendo o princípio ativo carvacol) e tomilho (somente o óleo essencial) em proporções iguais. Os extratos foram produzidos pela empresa Givaudan e sofreram microencapsulamento, para se minimizar o sabor dos óleos na dieta e liberá-los, de forma controlada, no estômago do animal.

A dieta basal fornecida aos animais (Tabela 1) antedeu os níveis estabelecidos por Rostagno et al. (2000). Os produtos utilizados como promotores de crescimento foram adicionados à dieta em substituição ao conteúdo inerte.

O escore de diarréia dos leitões (considerando-se 4, fezes normais e 1, fezes líquidas) foi avaliado diariamente. Ao final do experimento, quando os animais atingiram 56 dias de idade, após jejum de seis horas, um animal por parcela foi sacrificado, tendo o trato gastrintestinal exposto e o duodeno, jejuno, íleo e ceco coletados. Com o auxílio de uma lâmina cirúrgica estéril descartável, a mucosa do segmento foi exposta e o material foi coletado por raspagem, envasado em microtubos estéreis e mantido a $-80^{\circ} \mathrm{C}$ até o momento do processamento.

Para confecção da amostra composta (representativa das quatro repetições de cada tratamento), foram tomados dois gramas de cada amostra simples e o material homogeneizado. Foram confeccionadas 20 amostras compostas, considerando-se o tratamento e o segmento intestinal em questão (duodeno, jejuno, íleo ou ceco). Um grama da amostra composta foi submetido, a extração de DNA total, utilizando-se o kit FastDNA Spin (Bio 101, Vista, Califórnia), de acordo com as instruções do fabricante. Foi adicionado $1 \mathrm{~mL}$ da solução CLS-TC (solução de lise celular para tecidos animais e bactérias) a um microtubo de 1,5 $\mathrm{mL}, 100 \mathrm{mg}$ da amostra de interesse e um cilindro plástico de $1 / 4$ de polegada. Os tubos foram agitados, horizontalmente, por $10 \mathrm{~s} \mathrm{a} 4 \mathrm{~m} \mathrm{~s}^{-1}$, em um FP120 Fast Prep Cell Disruptor (Bio 101, Vista, Califórnia). Em seguida centrifugou-se o conteúdo dos tubos por $5 \mathrm{~min}$ a $13.000 \mathrm{~g} ; 600 \mathrm{~mL}$ de sobrenadante foram transferidos para um microtubo limpo, adicionado-se $600 \mathrm{~mL}$ de matriz de ligação (sílica) e agitando-se os tubos durante 1 minuto por inversão. Os tubos foram incubados por 5 min à temperatura ambiente e centrifugados por $30 \mathrm{~s}$, para a formação do pélete. O sobrenadante foi descartado, o pélete ressuspendido em $500 \mathrm{~mL}$ de solução de lavagem (SEWS) e incubado por 1 min à temperatura ambiente e a solução foi transferida para um filtro acoplado a um microtubo (Bio 101, Vista Califórnia). Os microtubos com filtro foram centrifugados duas vezes por $1 \mathrm{~min}$ a $13.000 \mathrm{~g}$. Os filtros foram transferidos para microtubos limpos, 
Tabela 1 - Composição percentual e valores calculados da ração basal

Table 1 - Composition (\%) and calculated values of the basal diet

\begin{tabular}{lc}
\hline Ingrediente & Dieta \\
Ingredient & Diet \\
\hline Milho (Corn) & 63,329 \\
Farelo de soja (Soybean meal) & 23,500 \\
Soro de leite (Dried whey) & 2,673 \\
Lactose (Lactose) & 2,992 \\
Plasma (Plasma) & 2,000 \\
Fosfato bicálcico (Dicalcium phosphate) & 1,497 \\
Calcário (Limestone) & 1,024 \\
Óleo de soja (Soybean oil) & 1,500 \\
L-Lisina 78\% (L-Lysine $78 \%)$ & 0,427 \\
L-Treonina (L-Threonine) & 0,162 \\
DL-Metionina 98\% (DL-Methionine 98\%) & 0,145 \\
L-Triptofano (L-Tryptophan) & 0,016 \\
Cloreto de colina 60\% (Choline chloride) & 0,100 \\
Mistura mineral (Mineral premix) & 1 \\
Mistura vitamínica (Vitamin premix) & 2 \\
Sal (Salt) & 0,100 \\
Inerte (Inert) & 0,100 \\
\hline
\end{tabular}

Composição calculada

Calculated composition

\begin{tabular}{lr}
\hline Energia metabolizável, kcal/kg (Metabolizable energy, kcal/kg) & $3.300,00$ \\
Proteína bruta, \% (Crude protein, \%) & 19,50 \\
Lisina total, \% (Total lysine, \%) & 1,33 \\
Lisina digestível, \% (Digestible lysine, \%) & 1,19 \\
Treonina digestível, \% (Digestible threonine, \%) & 0,77 \\
Triptofano digestível, \% (Digestible tryptophan, \%) & 0,21 \\
Metionina digestível, \% (Digestible methionine, \%) & 0,39 \\
Metionina + cistina digestível, \% (Digestible methionine plus cystine, \%) & 0,69 \\
Lactose, \% (Lactose, \%) & 4,00 \\
Cálcio, \% (Calcium, \%) & 0,87 \\
Fósforo disponível, \% (Available phosphorus, \%) & 0,42
\end{tabular}

${ }^{1}$ Quantidades supridas por kg de ração (Amount fed per kg of diet): vit. A, 6000 UI; vit. $D_{3}, 1500$ UI; vit. E, 15 UI; vit. $\mathrm{K}_{3}, 1,5 \mathrm{mg}$; vit. $\mathrm{B}_{1}, 1,35 \mathrm{mg}$; vit. $\mathrm{B}_{2}, 4 \mathrm{mg}$; vit. $\mathrm{B}_{6}, 2 \mathrm{mg}$; vit. $\mathrm{B}_{12}, 20 \mathrm{mg}$; ácido nicotínico (nicotinic acid), $20 \mathrm{mg}$; ácido fólico (folic acid), 0,6 mg; biotina (biotin), 0,8 mg; ácido pantotênico (pantothenic acid), 9,35 mg; selênio (selenium) 0,3 mg.

${ }^{2}$ Quantidades supridas por kg de ração (Amount fed per kg of diet): I, 1,5 mg; Co, 1 mg; Cu, 10 mg; Zn 100 mg; Fe, $100 \mathrm{mg}$; Mg, $40 \mathrm{mg}$.

onde foram adicionados $100 \mathrm{~mL}$ de solução DES à matriz de ligação. Incubou-se por 5 min à temperatura ambiente e centrifugou-se por 5 min a 13.000 g. Os filtros foram descartados e a solução de DNA puro foi coletada. A integridade do DNA total foi verificada por meio de eletroforese em gel de agarose 1,0\% 0,5X TBE (1X TBE: $45 \mathrm{mM}$ Tris-borato, $1 \mathrm{mM}$ EDTA, pH 8), utilizando-se um densitômetro laser FluorImagen (Molecular Dynamics) e o programa Fragment Analyses (Molecular Dynamics). A quantificação do DNA foi feita usando-se como padrão o Low DNA Mass Ladder (Gibco - BRL). O DNA foi armazenado a $-20^{\circ} \mathrm{C}$ até a análise.
Para amplificação de fragmentos específicos da região V3 do rDNA 16S de microrganismos de domínio Bacteria, utilizou-se o seguinte conjunto de iniciadores: BA338fCG (5’ CGC CCG CGC GCG GCG GGC GGG GCG GGG GCA GCA CGG GGG GAC TCC TAC GGG 3’) e UN518r (5’ ATT ACC GCG GCT GCT GG 3’) (Ovreas et al., 1997), em solução contendo 0,2 mM de cada dNTP, 1,5 mM $\mathrm{MgCl}_{2}$, 5 pmol de cada iniciador, 1,5U de Taq DNA Polimerase (Gibco BRL), 5 mL do tampão da reação 10X e 25 ng de DNA. O DNA foi adicionado após desnaturação inicial a $95^{\circ} \mathrm{C}$. A amplificação foi realizada em um termociclador (Mastercycler Gradient, Eppendorf), 
nas seguintes condições: desnaturação inicial durante 5 min a $95^{\circ} \mathrm{C}$; 30 ciclos de desnaturação a $95^{\circ} \mathrm{C}$ por 1 min, anelamento a $55^{\circ} \mathrm{C}$ por 1 min e extensão a $72^{\circ} \mathrm{C}$ durante $1 \mathrm{~min}$; extensão final a $72^{\circ} \mathrm{C}$ durante $10 \mathrm{~min}$. Uma alíquota dos produtos de PCR (amplicons) foi analisada por meio de eletroforese em gel de agarose a 1,0\% - 0,5X TBE, utilizando-se um densitômetro laser FluorImagen (Molecular Dynamics) e o programa Fragment Analyses (Molecular Dynamics), e quantificada usando-se como padrão o Low DNA Mass Ladder (Gibco - BRL).

Os amplicons do rDNA 16S foram separados por eletroforese em gel de poliacrilamida $8 \%$ com gradiente desnaturante variando de 15 a 55\%. O gradiente foi preparado utilizando-se duas soluções (solução $100 \%$ de desnaturação contendo 40\% (vol/vol) formamida e $7 \mathrm{M}$ uréia e solução $0 \%$ de desnaturação sem uréia ou formamida) (Ovreas et al., 1997). A DGGE foi realizada com auxílio do equipamento DCode (BioRad) em géis de 16 x 16 x 0,1 cm e tampão TAE 0,5X (20 mM Tris acetato e 0,5 mM EDTA). Foram aplicados $500 \mathrm{ng}$ de produto de PCR por canaleta. A eletroforese foi realizada a $200 \mathrm{~V}$ e $60^{\circ} \mathrm{C}$, durante quatro horas. Os géis foram fixados com ácido acético $10 \%$ por 20 min, lavados com água desionizada três vezes, imersos em metanol $50 \%$ por $20 \mathrm{~min}$, novamente lavados com água desionizada e corados com SYBR Green I (0,1 mL/mL) por 30 min. Após a coloração, os géis foram analisados utilizando-se um densitômetro laser FluorImagen (Molecular Dynamics) e o programa Fragment Analyses (Molecular Dynamics).

A análise dos dados de ganho diário de peso, conversão alimentar e incidência de diarréia foi realizada pelo procedimento General Linear Models do SAS (1998) e as médias foram comparadas por contrastes ortogonais (5\%).

A presença ou ausência dos amplicons detectados nas diferentes amostras foi utilizada na análise de agrupamento hierárquico, por intermédio do programa Systat 8.0 (1996), utilizando-se o algoritmo de Ward para ligação e distância em porcentagem como unidade de medida.

\section{Resultados e Discussão}

Acredita-se que a microbiota aderida ao aparelho digestório pode conferir proteções física, química e biológica contra a penetração de patógenos (Stern et al., 1994; Zhu et al., 2002) que podem reduzir o desempenho, além de estar relacionada diretamente a fatores digestivos e metabólicos (Krause et al., 1999). Considerando-se que a microbiota aderida ao epitélio difere da dispersa no lúmem intestinal e a separação desses materiais pode não ser tão eficiente quando efetuada em laboratório (Zhu et al., 2002), optou-se por manter os animais em jejum nas horas que antecederam o abate, para que se pudesse coletar somente a microbiota aderida ao tecido.

Preconiza-se que a microbiota intestinal é vasta e apenas 400 espécies são conhecidas (Moore et al., 1974; Abbott, 2004), sendo que muitas raramente são detectadas (Moore et al., 1995) por métodos tradicionais de cultivo. Recentemente, Leser et al. (2003) observaram 375 genótipos diferentes no trato intestinal de suínos. Neste estudo, os géis confeccionados a partir de amostras coletadas nos diferentes segmentos do trato intestinal de suínos permitiram a visualização de até 90 diferentes amplicons da região V3 do rDNA 16S (Figura 1), representando 90 espécies bacterianas distintas. Considerando-se a abundante diversidade apontada na literatura, a DGGE pode ter conduzido à subestimação no número de indivíduos encontrados, o que pode ter decorrido do fato de que algumas bactérias representam pequena parte da população intestinal e, conseqüentemente, na amostra o DNA das mesmas, podem representar menos de $1 \%$ do total (Muyzer \& Smalla, 1998). Segundo estes autores, isto implicaria em amplicons extremamente discretos, que não teriam seu perfil capturado durante a leitura em densitômetro. Outro motivo pelo qual o número de amplicons não correspondeu ao esperado seria a possível comigração de alguns fragmentos. É possível que algumas bandas não sejam fragmentos individuais, mas que tenham o mesmo conteúdo relativo de $\mathrm{C}+\mathrm{G}$ dentro do rDNA 16S e tiveram migração conjunta (Simpson et al., 1999). Mesmo com a limitação observada, a DGGE foi útil para avaliar diferenças na comunidade; se as amostras possuem padrões de migração diferentes, certamente as comunidades microbianas apresentam diferenças. Caso o padrão de migração seja o mesmo, então estas diferenças podem estar ou não presentes, havendo necessidade do emprego de outras técnicas para detectá-las (Cury, 2000).

As bactérias não são distribuídas ao acaso ao longo do trato intestinal, mas as diferentes espécies e os níveis populacionais distribuem-se de acordo com características específicas das regiões do trato 


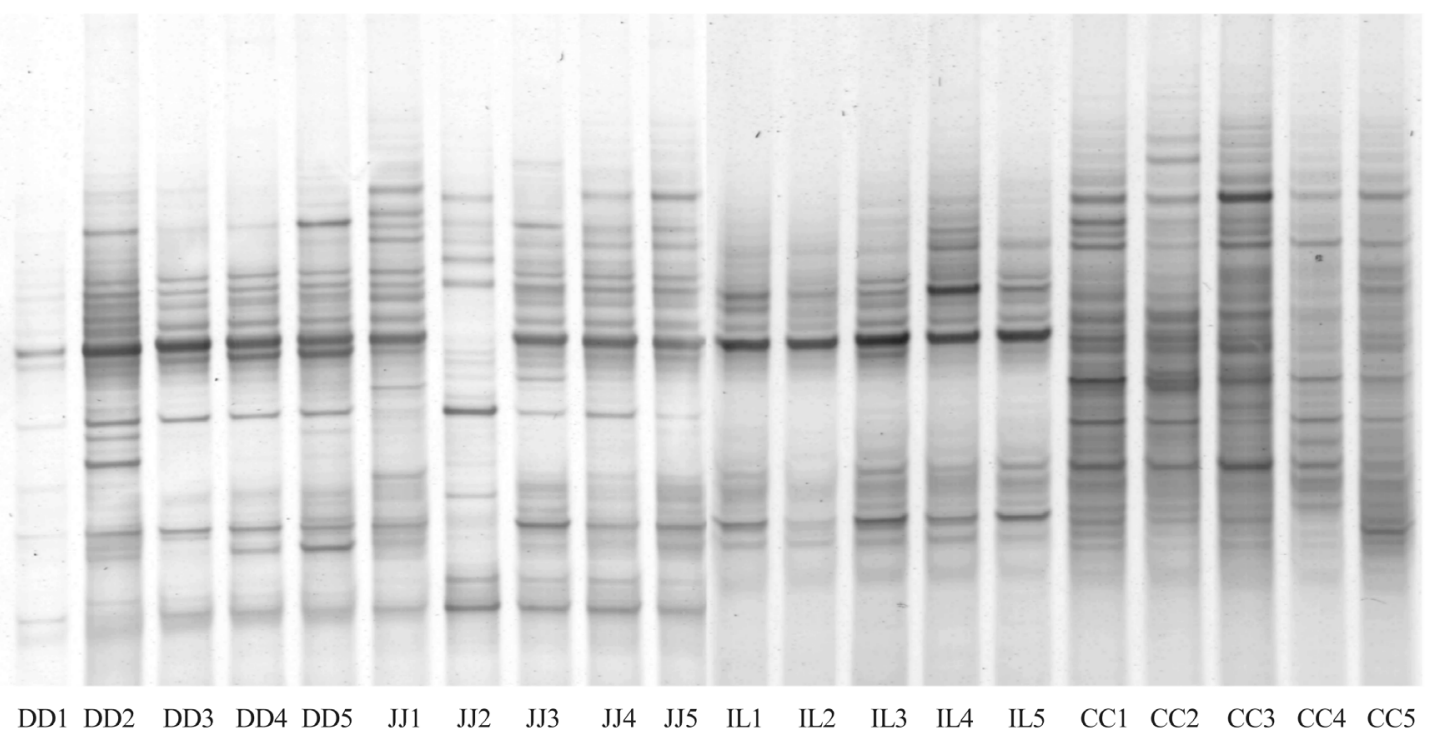

Figura 1 - DGGE de amplicons da região V3 do rDNA 16S de amostras da comunidade de Bacteria coletadas no duodeno (DD), jejuno (JJ), íleo (IL) e ceco (CC) de suínos de 35 a 56 dias de idade suplementados dieteticamente com dietas isentas de promotores de crescimento (1), antimicrobianos (2) ou extratos herbais nas concentrações de 700 ppm (3), 1.400 ppm (4) e 2.100 ppm (5).

Figure 1 - DGGE of amplicons 16S rDNA V3 region of bacteria population samples collected in duodennum (DD), jejunum (JJ), ileum (IL) and cecum (CC) of swine from 35 to 56 days old fed diet with growth promoter free (1), supplemented with antimicrobials (2) or herbal extracts at concentrations of $700 \mathrm{ppm}$ (3), 1,400 ppm (4) and 2,100 ppm (5).

(Mackie et al., 1999). Esta especificidade resulta de diferenças no $\mathrm{pH}$, da presença de enzimas digestivas e de sais biliares que podem modificar o trato intestinal criando "micro ambientes" nos quais a comunidade bacteriana será divergente.

Analisando a microbiota intestinal de suínos por meio de técnicas moleculares, Pryde et al. (1999) observaram diferenças no número de genótipos presentes nos diferentes segmentos analisados, o que também foi observado neste experimento. O número médio de amplicons no duodeno de suínos foi de 24, o que se deve ao fato de que esta região apresenta baixo $\mathrm{pH}$, em virtude da proximidade com o estômago e da alta taxa de passagem. Estes fatores possivelmente atuaram como barreira impedindo que a diversidade da comunidade de Bacteria do duodeno fosse elevada.

No terço médio do intestino delgado (jejuno), o número de amplicons se elevou para 31,6, reduzindo para 23,2 amplicons no terço final (íleo). É nas porções distais do intestino delgado que pode ocorrer a maior diversidade na microbiota (Mackie et al. 1999), podendo-se observar até 86 genótipos distintos no íleo (Leser et al., 2003), mas este fato não foi observado no último segmento estudado. É sabido que numerosos fatores podem influenciar a comunidade de
Bacteria do trato intestinal (Conway, 1997). Talvez o período de jejum a que os leitões foram submetidos tenha provocado alterações fisiológicas que tenham causado diminuição no número de espécies aderidas à vilosidade da região íleal. Knarreborg et al. (2002) afirmam que, em frangos, a microbiota do íleo e jejuno é similar, mas este fato não foi comprovado para a microbiota dos leitões nestes dois segmentos. Em aves, o íleo é uma região diminuta, enquanto, em suínos, é consideravelmente maior. A variação na composição da microbiota observada entre as duas espécies pode ser resultado da diferença anatômica entre elas (Van der Wielen et al., 2002).

Amostras coletadas no intestino grosso, especificamente no ceco, apresentaram o maior número médio de amplicons (33). Acredita-se que o grande número de bactérias presentes no intestino grosso - já foram observados 298 genótipos diferentes na região (Leser et al., 2003) - está relacionado ao fato de que a região apresenta lento turnover e grande quantidade de ácidos graxos de cadeia curta (Mackie at al., 1999).

O número médio de amplicons verificado nas amostras coletadas no duodeno, jejuno, íleo e ceco de suínos recebendo antimicrobianos (ANT) ou extratos herbais nas concentrações de 0 ppm (E0), 700 ppm 
(E700), 1400 ppm (E1.400) e 2100 ppm (E2.100) está representado na Figura 2. Foram observadas diferenças quanto ao número de amplicons presentes nos diferentes segmentos do trato intestinal dos leitões, em função da suplementação adotada. No terço inicial (duodeno), foi registrada a mais baixa abundância bacteriana entre todos os tratamentos nos animais não-suplementados, com apenas 14 amplicons identificados. A mais alta abundância no duodeno foi observada no tratamento com antimicrobianos, que apresentou 33 amplicons diferentes. No segmento seguinte (jejuno), o número de amplicons foi bastante semelhante, variando de 30 a 34 entre os diferentes tratamentos. No último segmento do intestino delgado (íleo), a maior abundância foi encontrada nos animais dos tratamentos E1400 e E2100, com 28 amplicons, e a menor, nos animais recebendo ANT (16 amplicons). O ceco apresentou maior abundância bacteriana nos suínos submetidos ao tratamento E0 (37 amplicons), e a menor abundância, nos animais recebendo E1400 (27 amplicons).

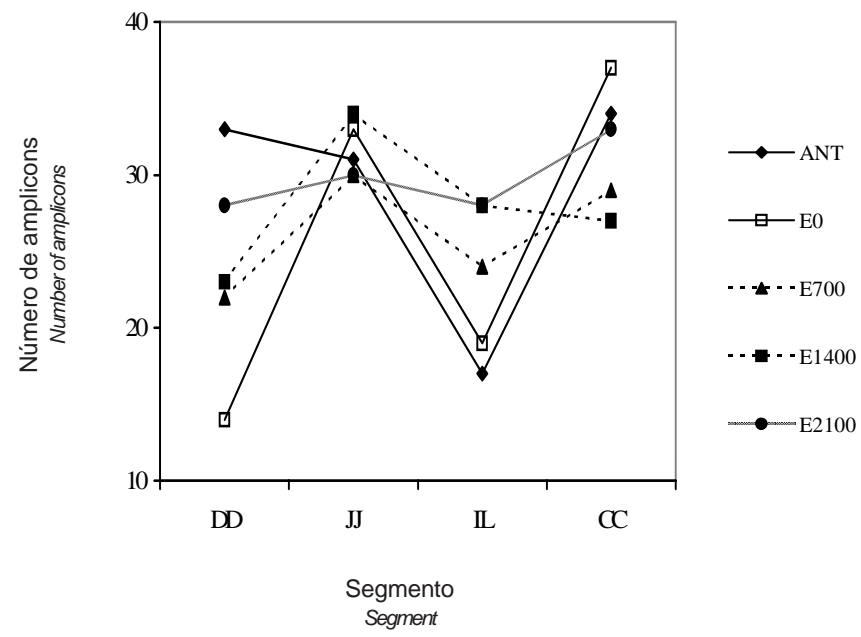

Figura 2 - Número de amplicons detectados nas amostras provenientes do duodeno (DD), jejuno (JJ), íleo (IL) e ceco (CC) de suínos suplementados dieteticamente com antimicrobianos (ANT) ou extratos herbais nas concentrações de 0 ppm (E00), 700 ppm (E700), 1.400 ppm (E1400) e 2.100 ppm (E2100).

Figure 2 - Number of amplicons detected in samples of duodenum (DD), jejunum (JJ), ileum (IL) and cecum (CC) of swine fed diets supplemented with antimicrobial (ANT) or herbal extracts at concentrations of $0 \mathrm{ppm}$ (E0), $700 \mathrm{ppm}$ (E700), 1,400 ppm (E1400), and 2,100 ppm (E2100).
Os antibióticos podem melhorar o desempenho zootécnico por meio da inibição da microbiota normal, levando ao aumento da utilização de nutrientes (Gaskin, et al., 2002). Neste experimento, os promotores de crescimento antimicrobianos utilizados não conduziram à diminuição no número de espécies bacterianas distintas observadas, com exceção ao íleo, em relação aos tratamentos com suplementação com diferentes concentrações de extratos herbais (E700, E1400 e E2100). Este fato é coerente com os dados de desempenho obtidos (Tabela 2), em que não foram observadas diferenças no ganho de peso, na conversão alimentar e na incidência de diarréia quando se comparou o efeito dos antibióticos com as diferentes concentrações de extratos herbais.

Os animais mantidos sem suplementação apresentaram discreta elevação no número de espécies bacterianas nos diferentes segmentos analisados, com exceção ao duodeno, em relação ao número de genótipos observados no trato intestinal de suínos suplementados comantimicrobianos. A incidência dediarréia também foi maior naquele tratamento (Tabela 2). A microbiota dos animais não-suplementados poderia conter alguma espécie bacteriana que seria responsável pelo aumento na incidência de diarréia. Deve-se considerar também que o aumento no número de diferentes genótipos bacterianos não foi muito pronunciado. Foram observados no jejuno, íleo e ceco, respectivamente, 2, 2 e 3 amplicons adicionais. Já foi verificado que a diarréia pode causar diminuição no número de genótipos bacterianos em diferentes segmentos do trato intestinal de suínos (Oli et al., 1998, Brigidi et al., 2001), o que pode ter contribuído para que não fosse observado número extremamente elevado de espécies bacterianas observadas por meio da DGGE.

Os extratos herbais não propiciaram aumento ou diminuição característica no número de espécies bacterianas, representada pelo número de amplicons visualizados em todos os segmentos do trato intestinal, observando-se a presença de um número intermediário de amplicons nos quatro segmentos analisados. Possivelmente as diferentes concentrações do promotor de crescimento alternativo tenham atuado modificando a composição da microbiota intestinal, permitindo o estabelecimento de microrganismos benéficos e resultando em efeito positivo no ganho de peso no tratamento E2100, em relação aos tratamentos E700 e E1400. O eugenol e o carvacol, princípios ativos do cravo e do orégano, respectivamente, já 
Tabela 2 - Valores médios de desempenho de suínos de 35 a 56 dias de idade suplementados dieteticamente com antimicrobianos (ANT) ou extratos herbais nas concentrações de 0 ppm (E0), 700 ppm (E700), 1.400 ppm (E1400) e 2.100 ppm (E2100), comparação de médias por contraste, valores de $\mathrm{F}$ e coeficiente de variação (CV)

Table 2 - Performance of swine from 35 to 56 days old fed diets supplemented with antimicrobials (ANT) or herbal extracts at concentrations of 0 ppm (EO), 700 ppm (E700), 1,400 ppm (E1400) and 2,100 ppm (E2100), means comparisons by contrast, $F$ value and coefficient of variation $(\mathrm{CV})$

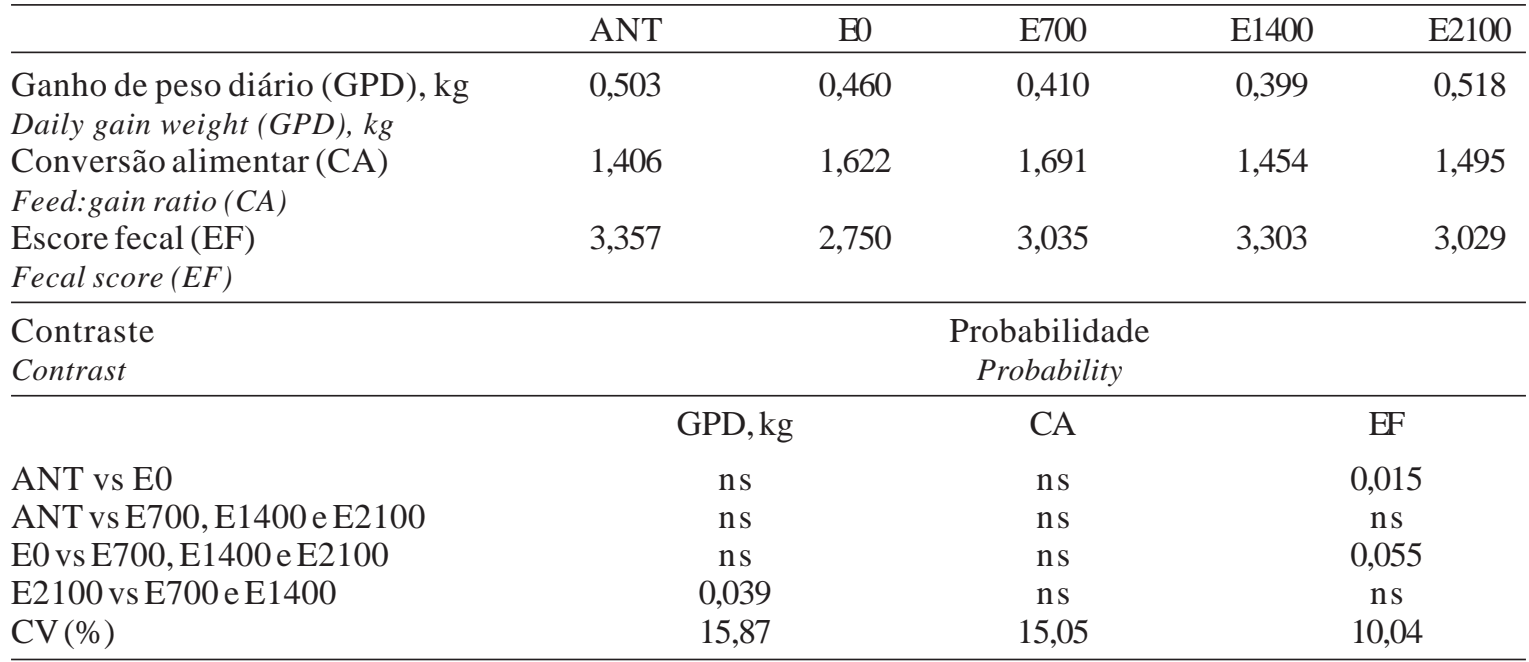

demonstraram efetividade na inibição de diferentes espécies bacterianas patogênicas (Kamel, 2001). Brugalli (2003) afirma que, para que um extrato herbal apresente efeito, este deve ser incluído em altas doses na dieta, o que foi confirmado no presente ensaio. Os efeitos da adoção de níveis superiores a 2.100 ppm como forma de se promover melhorias no desempenho e maiores modificações na microbiota bacteriana intestinal não foram estudados neste trabalho.

Tem-se preconizado que os promotores de crescimento atuem modificando a estrutura da microbiota intestinal. A estrutura é analisada através da visualização do padrão de migração dos amplicons na DGGE. A presença ou ausência de amplicons possibilita inferências sobre a estrutura da microbiota intestinal. A utilização de dendrogramas baseados no algoritmo de Ward possibilita que os efeitos dos tratamentos possam ser claramente observados (McCracken et al., 2001), mostrando-se uma maneira didática da avaliação.

Analisando o dendrograma gerado (Figura 3), observa-se que houve o agrupamento de amostras primeiramente em função do local de coleta, contrariando os relatos de Coolins \& Gibson (1999), que afirmam que a dieta pode exercer a maior influência sobre a constituição da população bacteriana. As estruturas da comunidade de Bacteria do trato intestinal de suínos apresentaram similaridade em função

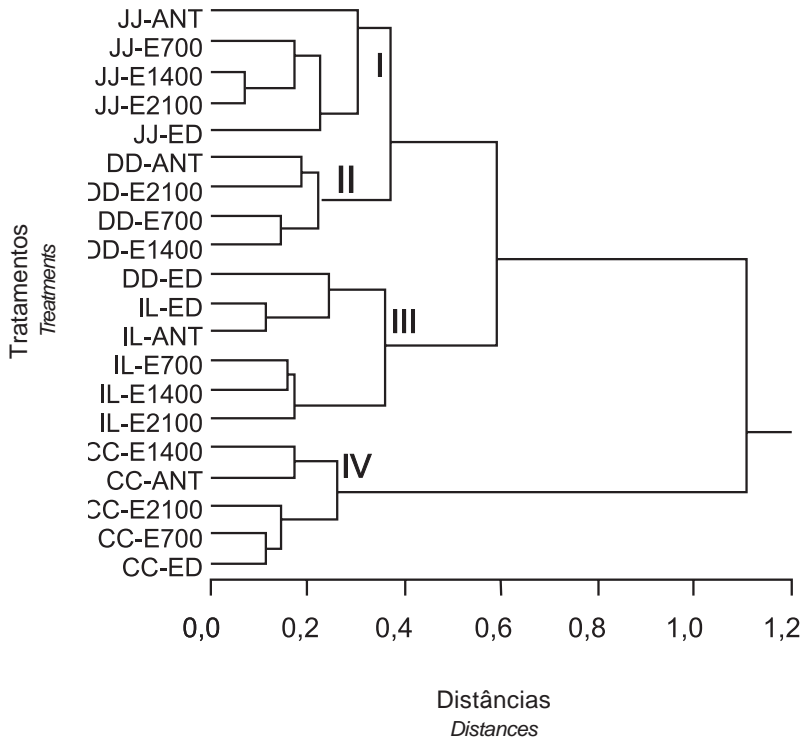

Figura 3 - Dendrograma representando as relações entre o padrão de bandeamento dos amplicons da região V3 do rDNA $16 \mathrm{~S}$ a partir de amostras da comunidade bacteriana intestinal do duodeno (DD), jejuno (JJ), íleo (IL) e ceco (CC) de suínos suplementados com antimicrobianos (ANT) ou extratos herbais nas concentrações de 0 ppm (E0), 700 ppm (E700), 1400 ppm (E1400) e 2100 ppm (E2100).

Figure 3 - Dendrogram representing the relationship between V3 region of $16 \mathrm{~S}$ rDNA amplicon banding patterns from samples of bacterial community of duodenum $(D D)$, jejunum (JJ), ileum (IL) and cecum (CC) of swine fed diets suplemented of antimicrobials (ANT) or herbal extracts at concentrations 0 ppm (EO), 0 ppm (E0), 700 ppm (E700), 1,400 ppm (E1400) and 2,100 ppm (E2100). 
do local de amostragem maior que em relação ao tratamento administrado. As estruturas das comunidades de Bacteria observadas nas amostras coletadas do jejuno (ramificação I) evidentemente agruparam-se, indicando maior similaridade entre si. As estruturas da comunidade de Bacteria observadas nas amostras oriundas do duodeno e íleo tenderam ao agrupamento (ramificações II e III) e aquelas presentes no ceco foram semelhrantes entre si e foram as que apresentaram menor similaridade com as estruturas observadas em outros compartimentos, formando uma ramificação distinta das demais (ramificação IV).

Em linhas gerais, não foi possível atribuir um padrão na estrutura da comunidade de Bacteria coletada no trato intestinal de suínos em relação à suplementação de diferentes promotores de crescimento. Observouse que, no jejuno e íleo, houve maior similaridade das estruturas da comunidade bacteriana das amostras coletadas de animais submetidos à suplementação com extratos herbais (E700, E1400 e E2100). No duodeno, amostras oriundas de animais suplementados com E2100 e ANT apresentaram a estrutura da comunidade de Bacteria muito semelhantes.

\section{Conclusões}

O antibiótico e o extrato herbal proporcionaram redução na incidência de diarréia.

O extrato herbal em diferentes concentrações proporcionou desempenho similar ao verificado em animais suplementados com antibiótico.

Onível de 2.100 ppm de extrato herbal proporcionou melhor ganho de peso que os menores níveis testados.

Foi possível estabelecer relações entre o número de diferentes amplicons observados nos quatro segmentos do trato intestinal, a suplementação adotada e a incidência de diarréia.

O número de amplicons detectados variou em função do segmento intestinal analisado.

As estruturas da comunidade de Bacteria do trato intestinal de suínos apresentaram maior similaridade em função do local de amostragem que em relação ao tratamento administrado.

\section{Literatura Citada}

ABBOTT, A. Gut reaction. Nature, v.427, n.6972, p.284-286, 2004.

BRIGIDI, P.; VITALI, B.; SWENNEN, E. et al. Effects of probiotic administration upon the composition and enzymatic activity of human fecal microbiota in patients with irritable bowel syndrome or functional diarrhea. Research in Microbiology, v.152, n.8, p.735-741, 2001.

BRUGALI, I. Alimentação alternativa: a utilização de fitoterápicos ou nutracêuticos como moduladores da imunidade e desempenho animal. In: SIMPÓSIO SOBRE MANEJO E NUTRIÇÃO DE AVES E SUÍNOS, 2003, Campinas. Anais... Campinas: Colégio Brasileiro de Nutrição Animal, 2002. p.167-182.

CONWAY, P. Development of intestinal microbiota. In: MACKIE, R.I.; WHITE, B.A.; ISAACSON, R.E. (Eds.). Gastrointestinal microbiology. New York: Chapman and Hall, 1997. p.3-38.

COOLINS, M.D.; GIBSON, G.R. Probiotics, prebiotics, and synbiotics: approaches for modulating the microbial ecology of the gut. The American Journal of Clinical Nutrition, v.69 (supplement), p.1052S-1057S.

CURY, J.C. Atividade microbiana e diversidade metabólica e genética em solos de mangue contaminados com petróleo. Piracicaba: Escola Superior de Agricultura "Luiz de Queiroz”, 2000.84p. Dissertação (Mestrado em Agronomia) - Escola Superior de Agricultura “Luiz de Queiroz”, 2000.

DEANS, S.G.; RITCHIE, G. Antibacterial properties of plant essential oils. International Journal of Food Microbiology, v.5, n.1, p.165-168, 1987.

FAIRBROTHER, J. Severe E. coli outbreak on the increase. In: Worldwide pig progress. Amsterdanm: Elsevier International: 1999. p.16-17.

GASKINS, H.R.; COLLIER, C.T.; ANDERSON, D.B. Antibiotics as growth promotants: mode of action. Animal Biotechnology, v.13, n.1, p.29-42, 2002.

KAMEL, C. Plant extracts in an integrated approach. Feed Mix, v.9, n.6, p.14-16, 2001.

KNARREBORG, A.; SIMON, M.A.; ENGBERG, R.M. Effects of dietary fat source and subtherapeutic levels of antibiotic on the bacterial community in the ileum of broiler chickens at various ages. Applied Environmental and Microbiology, v.68, n.12, p.5918-5924, 2002.

KRAUSE, D.O.; McSEENEY, C.S.; FORSTER, R.J. Molecular ecological methods to study fibrolitic ruminal bacteria: phlylogeny, competition and persistence. In: INTERNATIONAL SYMPOSIUM ON MICROBIAL ECOLOGY, 8., 1999, Halifax. Proceedings... Halifax:Atlantic Canadá society for Microbial Ecology, 1999. p.15-19.

LESER T.D.; AMENUVOR, J.Z.; JENSEN, T.K. et al. Cultureindependent analysis of gut bacteria: the pig gastrointestinal tract microbiota revisited. Applied and Environmental Microbiology, v.68, n.2, p.673-690, 2003.

MACKIE, R.I.; SGHIR, A.; GASKINS, H.R. Developmental microbial ecology of the neonatal gastrointestinal tract. The American Journal of Clinical Nutrition, v.69, p.1035S1045S, 1999 (supplement).

McCRACKEN, A.L.; SIMPSON, J.M.; MACKIE, R.I. et al. Molecular ecology analysis of dietary and antibiotic-induced alterations of the mouse intestinal microbiota. Nutrition Methodology, v.131, n.6, p.1862-1870, 2001.

MENTEN. J.F.M. Probióticos, prebióticos e aditivos fitogênicos na nutrição de aves. In: SINPÓSIO SOBRE INGREDIENTES NA ALIMENTAÇÃO ANIMAL, 2., 2002, Campinas. Anais... Campinas: Colégio Brasileiro de Nutrição Animal, 2002. p.251-276.

MOORE, W.E.C.; HOLDEMANN, L.V. Human fecal flora: the normal flora of 20 Japaneses-Hawaiians. Applied Microbioogy, v.27, n.5, p.961-979, 1974. 
MOORE, W.E.C.; MOORE, L.H. Intestinal floras of population that have a high risk of colon cancer. Applied and Environmental Microbiology, v.61, n.9, p.3202-3207, 1995.

MUYZER, G.; SMALLA, K. Application of denaturing gradient gel electrophoresis (DGGE) and temperature gradient gel electrophoresis (TGGE) in microbiol ecology. Antonie van Leeuwenhoek, v.73, n.1, p.127-141, 1998.

OLI, M.W.; PETSCHOW, B.W.; BUDDINGTON, R.K. Evaluation of fructooligosaccharide supplementation of oral electrolyte solutions for treatment of diarrhea: recovery of the intestinal bacteria. Digestive Disease Science, v.43, n.1, p.138-147, 1998.

OVREAS, L.; FORNEY, L.; DAAE, F.L. et al. Distribuition of bacterioplankton in meromic lake saelevannet, as determined by denaturing gradient electrophoresis of PCR-amplified gene fragments coding for 16S rRNA. Applied and Environmental Microbiology, v.63, n.9, p.3367-3373, 1997.

ROSTAGNO, H.S.; ALBINO, L.F.T.; DONZELE J.L. et al. Tabelas brasileiras para aves e suínos (Composição de alimentos exigências nutricionais). Viçosa, MG: Universidade Federal de Viçosa, 2000. 141p.

ROSTAGNO, H.S.; ALBINO, L.F.T. Nutritional evaluation of the $\mathrm{Xtract}^{\circledR}$ as an alternative to antibiotic growth promoters in broiler chicken diets. Degussa: 2001. 11p.

STATISTICAL ANALYSES SYSTEM - SAS. User's guide statistics. version 6.11. Cary: 1998. 634p.
SIMPSON, J.M.; McCRACKEN, V.J.; WHITE, B.A. et al. Application of denaturant gradient gel electrophoresis for the analysis of the porcine gastrointestinal microbiota. Journal Microbiological Methods, v.36, n.3, p.167-179, 1999.

STERN, N.J. Mucosal competitive exclusion to diminish colonization of chicken by Campylobacter jejuni. Poultry Science, v.73, n.3, p.402-407, 1994.

SYSTAT. User's guide statistics. version 9. Washington: 1996. 1085p.

PRYDE, S.; RICHARDSON, A.; STEWART, C. et al. Molecular analysis of the microbial diversity present in the colonic wall, colonic lumen, and cecal lumen of a pig. Applied and Environmental Microbiology, v.65, n.12, p.5372-5377, 1999.

van der WIELEN, P.W.J.J.; KEUZENKAMP, D.A.; LIPMAN, L.J.A. et al. Spatial and temporal variation of the intestinal bacterial community in commercially raised broiler chickens during growth. Microbial Ecology, v.44, n.3, p.286-293, 2002.

ZHU, X.Y.; ZHONG, T.; PANDYA, Y. et al. 16S rRNA-based analysis of microbiota from cecum of broiler chickens. Applied and Environmental Microbiology, v.68, n.1, p.124-137, 2002.

Recebido em: 18/02/04

Aceito em: 26/04/05 